\title{
Dermatofilose em ovinos da raça Santa Inês no Distrito Federal
}

\author{
[Dermatophylosis in Santa Inês sheep from Distrito Federal] \\ R.L. Castelo Branco, V.O. Drummond, H.H. Andrade, R.M.L.G. Lacerda, A.D.S.S. Marques, \\ M.R. Souza Mello, V.H.S. Oliveira, S. Perecmanis*, J.R.J. Borges \\ Faculdade de Agronomia e Medicina Veterinária - Universidade de Brasília - Brasília, DF
}

\section{RESUMO}

Relataram-se quatro casos de dermatofilose em ovinos da raça Santa Inês, no período de um ano. Microscopicamente observaram-se filamentos na forma de "trilho de bonde" e zoósporos nos quatro casos. A tentativa do isolamento do microrganismo foi realizada por meio do método de Haalstra e em apenas um caso obteve-se sucesso, observando-se colônias de aparência lisa, formato circular, cor amarelada e hemolítica em ágar sangue. O exame direto com coloração de Gram mostrou-se um método bastante eficiente na confirmação da presença do microrganismo afetando a epiderme em razão da morfologia típica do agente.

Palavras-chave: ovino, Santa Inês, dermatofilose

\begin{abstract}
Four cases of dermatophylosis were reported in Santa Inês sheep in a study period of one year. Microscopically, septate filaments and coccoid forms zoospores were observed. Attempts to isolate the microorganisms were accomplished using Haastra's method and it was successful in only one case. Dermatophilus congolensis samples have grown on blood agar, colonies where hemolytic, small, round and pigmentation vary from yellow to orange. The gram staining method was efficient to confirm the presence of the microorganism affecting the epidermis due to typical morphology of the agent.
\end{abstract}

Keywords: sheep, Santa Inês, dermatophylosis

\section{INTRODUÇÃO}

As infecções por Dermatophilus congolensis são designadas comumente por dermatofilose e estreptotricose cutânea (Carter, 1988; Quinn et al., 2005). Esta afecção é uma doença amplamente distribuída no mundo, porém apresenta maior prevalência em regiões úmidas, tropicais e subtropicais (Hyslop, 1979; Zaria, 1993). Diversos fatores estressantes, entre eles desmama, carência alimentar e traumatismos por manejo inapropriado, associados a períodos chuvosos e quentes, promovem um desequilíbrio das barreiras superficiais de defesa imunológica e inespecíficas ( $\mathrm{pH}$, ácidos graxos e flora normal), quebrando a integridade da pele e permitindo que os zoósporos de $D$. congolensis invadam o tegumento e produzam a dermatite bacteriana (Pereira e Meireles, 2007). Além disso, condições microambientais que interferem em mecanismos normais de proteção superficial, como secreção sebácea, também levam à ativação dos zoósporos dormentes. Quando estes são ativados, produzem tubos germinativos, os quais se desenvolvem em filamentos que invadem a epiderme (Quinn et al., 2005). A invasão bacteriana é seguida de uma resposta inflamatória aguda mediada por neutrófilos, a qual leva à formação de microabscessos no interior da epiderme, impedindo a progressão da bactéria e permitindo a regeneração dela (Pereira e Meireles, 2007).

Esse ciclo de invasão bacteriana, inflamação e regeneração da epiderme é o responsável pela formação das crostas pustulares multilaminadas que caracterizam clinicamente a enfermidade (Msami et al., 2001; Pereira e Meireles, 2007). A

Recebido em 15 de março de 2011

Aceito em 15 de maio de 2012

*Autor para correspondência (corresponding author)

E-mail: perecmaniss@unb.br 
doença tem evolução aguda, subaguda ou crônica, podendo acometer com maior frequência os bovinos, ovinos e equinos (Hyslop, 1979; Cunha et al., 2010), e ocasionalmente os suínos, caninos, felinos e humanos (Msami et al., 2001; Birgel et al., 2006).

O D. congolensis é uma bactéria Gram-positiva que pertence à classe dos actinomicetos. $\mathrm{O}$ agente tem por características o crescimento lento, a produção de filamentos ramificados e é considerado aeróbio ou anaeróbio facultativo, bem como capnofílico (Quinn et al., 2005; Pereira e Meireles, 2007). Além disso, seus zoósporos móveis, quando em condições adequadas, como em temperatura elevada e umidade, podem se proliferar e desenvolver a doença (Hyslop, 1979; Oliveira, 2000). Embora o D. congolensis esteja presente na pele de muitos animais clinicamente normais, age como um agente oportunista (Quinn et al., 2005; Macêdo et al., 2008). O objetivo deste trabalho consistiu em relatar quatro casos de dermatofilose ovina, diagnosticados no período de um ano.

\section{MATERIAL E MÉTODOS}

Foram coletadas, com auxílio de luvas, pinças e placas estéreis, crostas de quatro ovinos adultos da raça Santa Inês, sendo três fêmeas e um macho. As lesões encontradas nos animais foram localizadas espacialmente para correlação com a literatura existente.

O animal número 1 apresentava áreas de alopecia por todo o corpo, com crostas nas orelhas, na cabeça, no dorso e nos membros pélvicos e torácicos. $\mathrm{O}$ animal número 2 apresentava lesões crostosas somente no dorso e no lombo, enquanto os animais 3 e 4 apresentavam regiões alopécicas por todo o corpo e presença de crostas no dorso, na cabeça e nas orelhas. As crostas, em todos os casos, destacavam-se facilmente por simples torção.

Ao chegarem ao laboratório, as amostras foram trituradas com bisturi e umedecidas com solução salina estéril. Logo em seguida, foram feitas impressões diretas da face inferior das crostas em lâminas, sendo coradas pelo método de Gram para exame direto e pesquisa de estruturas filamentosas com padrão característico de "trilho de bonde". Além disso, foi realizado o isolamento do microrganismo por meio do método de Haalstra, conforme descrito por Quinn et al. (1994).

\section{RESULTADOS}

Microscopicamente, foram observados filamentos na forma de "trilho de bonde" $\mathrm{e}$ zoósporos em todos os quatro casos relatados, característicos de D. congolensis.

A tentativa de isolamento pelo método de Haalstra teve sucesso em apenas um caso, sendo que, após 48 horas de incubação a $37^{\circ} \mathrm{C}$ e sob uma atmosfera de 5-10\% de $\mathrm{CO}_{2}$, observou-se o crescimento de colônias de aparência lisa, formato circular, cor amarelada e hemolítica em ágar sangue ovino 5\%, também características de D. congolensis.

\section{DISCUSSÃO}

A porcentagem de casos confirmados pelo exame direto no presente relato foi semelhante ao encontrado por Santos et al. (2010), os quais coletaram crostas de 26 cordeiros que apresentavam lesões características de dermatofilose e, pelo exame direto das crostas, confirmaram que todos os animais estavam infectados pelo agente causador.

As características das colônias isoladas estão de acordo com o descrito por Quinn et al. (2005) e semelhantes às encontradas por Leoni et al. (1993). Percentualmente, Santos et al. (2010) encontraram resultado próximo ao presente relato, sendo que de 26 casos de dermatofilose em cordeiros confirmados por exame direto conseguiu-se isolar nove amostras em cultura pura de D. congolensis.

Discordando do presente relato, Pereira e Meireles (2007) afirmaram que o diagnóstico presuntivo da dermatofilose é determinado pela epidemiologia da doença, por sinais clínicos e pela visualização da bactéria em forma filamentosa, em esfregaços corados pelos métodos Gram ou Giemsa. Além disso, esses autores afirmam que o diagnóstico definitivo é realizado pelo isolamento e pela caracterização da bactéria por meio de crostas ou também de biópsia da lesão. Por outro lado, concordando com a metodologia utilizada e os achados laboratoriais, Olinda et al. (2009) defenderam a 
ideia de que o esfregaço corado pelo método Gram permite a rápida confirmação do diagnóstico clínico da dermatofilose, antes mesmo que se obtenha o resultado positivo para cultura bacteriana. Ademais, Olinda et al. (2009) consideraram os achados microscópicos de esfregaço como diagnósticos da infecção por $D$. congolensis.

A dermatofilose ovina foi estudada pela primeira vez no estado de São Paulo, em General Salgado, divisão regional agrícola de Araçatuba. Naquele estudo, verificou-se elevada prevalência, 95,8\%, atingindo tanto animais jovens como adultos, com ausência de infecção proliferativa das extremidades (Arantes et al., 1977), o que diferiu do presente relato, em que se verificaram casos somente em animais adultos e também em animais acometidos pela enfermidade em suas extremidades, como orelhas, membros pélvicos e torácicos. Além disso, o caso descrito no estado de São Paulo chama atenção por sua ocorrência ter sido em um período seco, contrariando a sazonalidade em virtude de a doença ocorrer, principalmente, em épocas úmidas e quentes (Pereira e Meireles, 2007).

A localização das lesões foi semelhante aos oito casos de dermatofilose em ovinos relatados por Macêdo et al. (2008), sendo diferentes apenas quanto às lesões encontradas nos membros pélvicos neste presente relato. Com relação à idade dos animais dos oito casos supracitados, verificou-se o acometimento de animais adultos e jovens, diferentemente deste relato, em que os quatro casos de dermatofilose ocorreram somente em animais adultos. Diferindo do presente relato, Leoni et al. (1993) observaram, na Itália, um ovino, adulto, naturalmente infectado por D. congolensis, com lesões crostosas localizadas na região do pescoço.

\section{CONCLUSÃO}

Os quatro casos de dermatofilose foram confirmados pela presença de filamentos na forma de "trilho de bonde" e zoósporos, além do cultivo positivo de uma das amostras. A utilização do exame direto com coloração de Gram mostrou-se bastante eficaz na confirmação da presença de D. congolensis afetando a epiderme em razão da morfologia típica do agente.

\section{REFERÊNCIAS}

ARANTES, I.G.; FISCHAN, O.; PORTUGAL, M.A.S.C. et al. Dermatophilosis in sheep from São Paulo (Brazil). Mycoses, v.20, p.83-88, 1977.

BIRGEL JUNIOR, E.H.; DAGLI, M.L.Z.; BENITES, N.R. et al. Ocorrência de dermatofilose (Dermatophilus congolensis) em suínos criados no Estado de São Paulo, Brasil. Arq. Inst. Biol., v.73, p.361-364, 2006.

CARTER, G.R. Actinomicetos, Nocardia e Dermatófilos. In: Fundamentos de Bacteriologia e Micologia Veterinária, 1.ed. São Paulo: Roca, 1988. p.195-200.

CUNHA, P.H.J.; SIQUEIRA, A.K.; FILHO, J.P.O. et al. Dermatofilose em bovinos criados em regime de confinamento. Vet. Zootec., v.17, p.224-228, 2010.

HYSLOP, N.St.G. Dermatophilosis (streptothricosis) in animals and man. Comp. Immunol. Microbiol. Inf. Dis., v.2, p.389-404, 1979.

LEONI, A.; FADDA, M.; NIEDDU, A.M. et al. Dermatophilosis in sheep: First report in Italy, experimental reproduction and evaluation of immune response. Boll. Soc. It. Biol. Sper., v.69, p.775-782, 1993.

MACÊDO, J.T.S.A.; RIET-CORREA, F.; DANTAS, A.F.M.; SIMÕES, S.V.D. Doenças da pele de caprinos e ovinos no semi-árido brasileiro. Pesq. Vet. Bras., v.28, p.633-642, 2008.

MSAMI, H.M.; KHASCHABI, D.; SCHOPF, A.M. et al. Dermatophilus congolensis infection in Goats in Tanzania. Trop. Anim. Health. Prod., v.33, p.367-377, 2001.

OLINDA, R.G.; CÂMARA, A.C.L.; FEIJÓ, F.M.C. Primeiro relato de dermatofilose generalizada em equino no Rio Grande do Norte. Acta Vet. Bras., v.3, p.187-192, 2009.

OLIVEIRA, S.J. Microbiologia Veterinária: Guia bacteriológico prático. 2.ed. Canoas: ULBRA, 2000. 237p.

PEREIRA, D.B.; MEIRELES, M.C.A. Dermatofiolose. In: RIET-CORREA, F.; SCHILD, A.L.; LEMOS, R.A.A.; BORGES, J.R.J. (Eds). Doenças de Ruminantes e Equídeos, v.1. 3.ed. Santa Maria: PALLOTI, 2007. p.280286. 
QUINN, P.J.; CARTER, M.E.; MARKEY, B.; CARTER, G.R. The Actinomycetes. In: Clinical veterinary microbiology. London: WOLF, 1994. p.144-155.

QUINN, P.J.; MARKEY, B.K.; CARTER, M.E. et al. Actinomicetos. In: Microbiologia Veterinária e Doenças Infecciosas. Porto Alegre: ARTMED, 2005. p.74-82.

SANTOS, A.S.; ALBUQUERQUE, P.P.F.; NETO, O.L.S. et al. Avaliação de diferentes tratamentos para dermatofilose de cordeiros. $X$ JORNADA DE ENSINO E EXTENSÃO - 2010. Recife: UFRPE, 2010. Disponível em: <http://www.sigeventos.com.br/jepex/inscricao/ resumos/0001/R0736-1.PDF>. Acessado em: 04 nov. 2010.
ZARIA, L.T. Dermatophilus congolensis infection (dermatophilosis) in animals and man! An update. Comp. Immunol. Microbiol. Inf. Dis., v.16, p.179-222, 1993. 